\title{
SRH commissioning in England: moving beyond transition
}

\section{Chris Wilkinson}

President, Faculty of Sexual \& Reproductive Healthcare, London, UK

\section{Correspondence to} Dr Chris Wilkinson, Faculty of Sexual \& Reproductive Healthcare, 27 Sussex Place, London NW1 4RG, UK: President@FSRH.org

Received 5 November 2014 Accepted 11 November 2014

\section{CrossMark}

To cite: Wilkinson C. J Fam Plann Reprod Health Care 2015;41:5-7.

\section{BACKGROUND}

Sexual and reproductive healthcare (SRH) is highly cost effective. ${ }^{1}{ }^{2}$ Of all modern healthcare interventions, contraception has had one of the most profound and positive effects on the health of women and society. In the UK, the extent of the benefit is not always recognised, but the importance of access to care has been. This is not the case globally: there is still significant political and religious opposition to contraception and good SRH in many regions of the world, which impacts on women's health and wellbeing. From a woman's perspective, contraception and sexual health are seen as an integral part of women's health, and part of a continuum with gynaecological care. Yet gynaecology, contraception and sexual health as separate entities are a remnant of historic medical divisions. For the individual woman, it is inappropriate to separate them.

The clinics historically known as family planning clinics provided far more than contraception. They were holistic services, mostly developed by women for women, and were safe places for women to seek care as complementary services to general practice. Those who led the development of these services, and similar services in general practice, understood the importance of good gynaecological care, contraceptive choice, of planning when to have a family, family spacing or abortion, and the impact of sexual ill health and sexual violence. Poor provision of care impacts socially and economically on women, families and society, and while this is generally understood, there is still inequity in attitude amongst healthcare professionals and in service delivery. This means that the provision of open-access womencentred health services is essential.

\section{CHANGING SERVICES}

Over the last 15 years, specialist services and general practices providing SRH care, including sexually transmitted infection (STI) care, have undergone major changes; this modernisation was mostly driven by clinicians wanting to improve both the public health and the health of individual men and women. There have been significant changes in the structure and training of the multidisciplinary team, increased outreach and community-based care, introduction of near-patient testing and promotion of self-management, and general practice has been able to integrate more SRH into routine management.

The changes to the structures put in place to manage English healthcare following the present Government's Health and Social Care Act of 2012 seem to be in the distant past and we are told that the transition is over. Public Health England (PHE) has been functional for 18 months and is to be congratulated on appointing a clinical advisor in SRH. Local authorities are commissioning (or procuring) sexual health services. NHS England, through specialised commissioning and the general practitioner (GP) contract, are commissioning HIV care and 'non-LARC' GP contraception, respectively, and the Clinical Commissioning Groups (CCGs) are commissioning abortion. However, for many, especially clinicians and those managing services, it does not feel as if the transition is over. While there are examples of good commissioning, there are many uncertainties. Services for men and women are changing and arguably often not as a result of good commissioning or for the benefit of those who need the service. So should we just get on with providing care, or should we be concerned?

\section{WHAT CONCERNS ARE THERE?}

- There is uncertainty around contracts and tendering decisions, both for general practices delivering longacting reversible contraception (LARC) and for specialist mandated services 
There is a lack of understanding that building good clinical teams and having appropriate clinical space requires both time and investment and that both need to be maintained. Uncertainty leads to loss of staff and lack of investment in services, especially in the year before a tendering process. As we move into 2015 this will probably be most notable when looking at the provision of LARC in general practice, where many are still unaware whether they are to be commissioned this year and, faced with uncertainty, practices may put their limited resources elsewhere. ${ }^{3}$

- There is uncertainty about what actually should be commissioned, and for whom

Regulations within the Health and Social Care Act mandate local authorities "to provide comprehensive, open-access STI testing and treatment and contraceptive services for everyone present in their area", which on the face of it sounds good. However, some are interpreting "everyone present in their area" to mean local residents, and there are reports of women being denied access to some highly effective methods of contraception if they do not live within the borough or are not registered with a local GP.

The Health and Wellbeing Boards are statutory bodies introduced under the Health and Social Care Act 2012 to improve integration between National Health Service (NHS) healthcare, social care, and public services so that service users experience more joined-up care, yet few have SRH on their agenda. Examples where this integration, or women-centred care, appears to be moving backwards include the management of the common condition of heavy menstrual bleeding. Community services can work with general practice to ensure that all women have access to care without the need for hospital referral, but in some areas this is now no longer possible, resulting in prolonged patient journeys through the healthcare system. We also have reports of SRH services no longer being commissioned to take part in the NHS Cervical Screening Programme on the basis that cervical screening is not a part of contraception.

- The fragmentation of commissioning responsibilities leads to poorly coordinated decisions that impact on services and patient care

Examples include genitourinary medicine (GUM) services that have been put out to tender without considering the impact on HIV treatment and care services. Recently a decision to decommission a local NHS abortion provider, one of the few providers of late abortions in the country, will limit access to late abortion over a much wider area. This service is not needed frequently, but its availability is critical for women who do require it.

- Differential payment mechanisms have distorted the provision of care

In many areas GUM activity is on the national Payment by Results (PbR) tariff, payment based on activity, whereas SRH activity is on block contract, a fixed payment irrespective of levels of activity. Even with negotiated 'caps' or 'collars' for PbR (mechanisms to limit expenditure with increased activity), this acts as an incentive for providers to encourage STI care and to limit contraceptive care, an anomaly that distorts delivery of care and investment in contraceptive services irrespective of need.

- Provider organisations may centralise services to make savings

As financial pressures increase for all NHS provider organisations, cost-cutting has led to the relocation of services provided by some hospital trusts to cheaper locations rather than where the local need is. An example is the closure of community or town centre clinics with movement of the delivery of care into hospital premises.

\section{LOCALISM AND TENDERING}

The Teenage Pregnancy Strategy demonstrated the importance of joined-up approaches to SRH and the role that local authorities play. Local problems need local solutions. Levels of sexual ill health and location of higher-risk populations vary significantly, sometimes over quite small distances. A locally tailored approach is required for some aspects of provision of $\mathrm{SRH}$, and local authority public health departments are in the best place to guide this.

However, all women of reproductive age who are heterosexually active and who do not want to plan a pregnancy require information about, and access to, contraception. The need to seek advice about contraception may be planned or unplanned and, as such, requires widely available accessible services.

Local authorities are required to get value for money. This may be interpreted to mean that services should always be put out to tender. However, tendering is not mandatory and while tendering looks proactive, it is expensive for all sides; it destabilises services and does not necessarily lead to improved care or access. This is especially true where contracts for only 3 years are put in place. It is also difficult for some voluntary sector providers to respond to calls to tender and their significant expertise and skills may therefore be lost.

An alternative view being put forward by some enlightened commissioners is that tendering should be a last resort and getting the most value for money requires close working between themselves and services - the clinicians and service managers with public and patient involvement to plan and develop those services. Clinicians working in frontline services provide care for local people and know the local issues; they should be seen as partners by commissioners.

\section{FINAL THOUGHTS: WHERE NOW?}

Despite providing secondary care referral services and significant amounts of training to NHS staff, the 
sexual health services in England are technically no longer NHS services. It is not clear how training will be maintained in all places where it is needed. Local authorities receive a ring-fenced Public Health Grant from Government that was intended to enable relevant local authorities to discharge their new public health responsibilities. The ring fence is time-limited and the uplift in NHS spending announced recently does not apply to the Public Health Grant. Both these situations pose a risk to the provision of SRH care.

General practice and specialist SRH services provide a vital public health role but also deliver healthcare to individuals that inextricably interdigitates with care provided by the NHS. Under the current structures in England, the role of the Health and Wellbeing Boards in ensuring high-quality SRH care is therefore fundamental. In September 2014, PHE published a guide to whole system commissioning, 'Making it Work'. ${ }^{4}$ This document is an essential reference for all those involved in the procurement and management of SRH services.

So as clinicians delivering SRH care we are right to try to make this transition work for patients and we are right to work with commissioners across the local authority - NHS interface to make it happen, keeping patients at the centre of their own care. We are also right to voice our concerns and we have a responsibility to question, challenge and speak up when patient care is being compromised.

We should set as our ambition that SRH should be one of the key measures of quality in local healthcare programmes. However, to achieve this will require a number of changes to the current arrangements. First, introduction of a single mechanism for payment across SRH and GUM is urgently needed to ensure value for money, the integration of care, and to avoid unintended variations in access to care between contraception and STI care. Second, to increase the likelihood that care is integrated around the individual, NHS and public health planning and commissioning need to be much closer, if not actually brought together. Finally, good data are essential, to enable analysis nationally down to local authority ward level; the dataset needs to be non-service-specific and to include a wider range of SRH outcomes and provision of care than is currently available. In this way we can start to ensure that the quality of SRH care provided to both women and men becomes a more central feature of local health planning.

Competing interests None.

Provenance and peer review Commissioned; internally peer reviewed.

\section{REFERENCES}

1 Armstrong N, Donaldson C. A systematic review of economic evaluations of contraceptive and abortion services and methods: their relevance to current policy in England. In: The Economics of Sexual Health in England. 2005. http://www.fpa. org.uk/sites/default/files/economics-of-sexual-health.pdf [accessed 6 November 2014].

2 National Institute for Health and Clinical Excellence (NICE). National Cost-Impact Report. Implementing the NICE Clinical Guideline on Long-Acting Reversible Contraception. (NICE Clinical Guideline No. 30.) 2005. http://www.nice.org.uk/ guidance/cg30/resources/longacting-reversible-contraceptioncost-impact-report2 [accessed 6 November 2014].

3 Primary Care Women's Health Forum. Members' Survey 2014. http://www.pcwhf.co.uk/images/LARC_survey.pdf [accessed 24 November 2014].

4 Public Health England. Making it Work: A Guide to Whole System Commissioning for Sexual Health, Reproductive Health and HIV. 5 September 2014. https://www.gov.uk/government/ publications/commissioning-sexual-health-reproductive-healthand-hiv-services [accessed 6 November 2014]. 